\title{
Relevância dos soft skills em gerenciamento de projetos globais
}

Nadia Pedrosa, Deivison Feitosa

Pós Graduação em Gestão de Tecnologia da Informação na Faculdade de Informática e Administração Paulista

nadia_pedrosa@hotmail.com

Deivison Feitosa

Pós Graduação em Tecnologia da Informação na Uninove

deivisonfeitosa@gmail.com

Cristina Dai Prá Martens

Doutora e Diretora do Programa de Mestrado Profissional em Administração - Gestão de Projetos MPA-GP, Uninove, São Paulo, Brasil

cristinadpmartens@gmail.com>

Luciano Ferreira da Silva

Doutor e Professor do Programa de Mestrado Profissional em Administração - Gestão de Projetos na Universidade Nove de Julho - Uninove

lf_silvabr@yahoo.com.br

Editor Científico: José Edson Lara

Organização Comitê Científico

Double Blind Review pelo SEER/OJS

Recebido em 19.02.2018

Aprovado em 06.11.2018 


\title{
Resumo
}

O gerenciamento de projetos globais se apresenta como um dos fatores para o alcance de sucesso das organizações que possuem seus negócios em diferentes países. Um aspecto importante neste contexto é que há uma relação positiva entre os soft skills dos gerentes de projetos e o sucesso dos projetos. Este relato técnico tem como objetivo analisar a relevância dos soft skills em gerenciamento de projetos globais por meio de um estudo de caso. Os resultados demonstraram a importância que os soft skills do gerente de projetos teve no sucesso do projeto analisado. Esta pesquisa apresenta contribuições tanto para estudos acadêmicos, ao demonstrar o destaque que o assunto soft skills possui dentro da disciplina de gerenciamento de projetos, quanto para o mundo corporativo, porque ressalta que os soft skills apresentados neste trabalho poderão se tornar uma lista de pré-requisitos demandados por um contratante ao recrutar gerentes de projetos para projetos globais.

Palavras-chave: Projetos globais; Soft skills; Gerente de projetos.

\begin{abstract}
The global project management has been presented as one of the factors to reach success for the organizations which own enterprise business in different countries. Therefore, an evident aspect in this context is the existence of a positive relation between project managers' soft skills and success of the projects. This technical report aims to present the soft skills' relevance in global project management through a case study carried out in an European multinational organization. The results prove the importance the project managers' soft skills had in success of the analyzed global project. This research presents contributions both to academy when it demonstrates the prominence that the subject soft skills has for project management discipline and to corporative world because the soft skills presented in this job might be part of a requirements list demanded by a contractor while recruiting a project manager for global projects.
\end{abstract}

Keywords: Global projects; Soft Skills; Project managers.

\section{Resumen}

La gestión de proyectos globales se presenta como uno de los factores para el éxito de las organizaciones que poseen sus negocios en diferentes países. Un aspecto evidente es que hay una relación positiva entre los soft skills de los gerentes de proyectos y el éxito de los proyectos. Este relato técnico tiene como objetivo analizar la relevancia de los soft skills en gestión de proyectos globales por medio de un estudio de caso. Los resultados demostraron la importancia que los soft skills del gerente de proyectos tuvieron en el éxito del proyecto analizado. Esta investigación presenta contribuciones tanto a estudios académicos al demostrar el destaque que el tema soft skills posee dentro de la disciplina de gestión de proyectos y del mundo corporativo porque resalta que los soft skills presentadas en este trabajo podrán convertirse en una lista de prerrequisitos demandados por un contratista al reclutar gerentes de proyectos.

Palabras claves: Proyectos globales; Soft skills; Gerente de proyectos 


\section{Introdução}

As empresas, em diversas localidades do planeta, são cada vez mais influenciadas por um mercado global, sendo esse não somente um ambiente para comercialização, mas também para a busca de recursos. Essa situação faz com que seus gestores procurem novas formas de produzir e comercializar bens e serviços (Fleury \& Fleury, 2003). As empresas que se propõem a atuar de forma global devem lidar com recursos espalhados em diferentes países, e até mesmo continentes, o que gera muitos desafios aos seus gestores.

Uma realidade que empresas multinacionais devem enfrentar é que os membros de suas equipes estão distantes uns dos outros, distribuídos em escritórios ao redor do mundo (Rodriques, 2010; Watanuki, Nadae, \& Carvalho, 2014). Apesar disso, os gerentes devem promover a manutenção do foco nos objetivos estratégicos da empresa. Assim, é possível entender a forma básica de estruturação das equipes de projetos globais de empresas multinacionais.

O tema gestão de projetos globais já foi tratado em estudos anteriores, estando entre eles os seguintes: Rodrigues (2010) analisou a gestão de equipes com base nas dimensões da cultura; Piscopo e Sbragia (2012) estudaram inovação e satisfação dos clientes; e, Steffey e Anantatmula (2011) estudaram questões relacionadas ao risco em projetos globais. A relevância deste tema pode ser evidenciada também em diversos projetos no âmbito público e/ou privado, sendo necessário explicitar que dada à complexidade de muitos problemas neste início do século XXI, questões locais são tratadas com equipes transnacionais (Watanuki et al., 2014).

Recai sobre o gerente de projetos a responsabilidade de conduzir projetos cada vez mais críticos diante do cenário competitivo. A necessidade concomitante de gerir pessoas para somar esforços que resultem em um produto ou serviço únicos exige do gerente de projetos habilidades éticas, interpessoais e conceituais (PMI, 2013). Em especial, o uso das habilidades interpessoais ou soft skills tem sido alvo de estudiosos que buscam entender os motivos que explicam o fato de projetos complexos igualmente geridos por gerentes de projetos experientes possuírem desempenhos distintos.

Este relato técnico pretende responder a seguinte questão: como o uso dos soft skills do gerente de projetos favorece o gerenciamento de projetos globais? Para isso, tem como objetivo analisar a relevância dos soft skills em gerenciamento de projetos globais. Como método, foi realizado um estudo de caso em uma organização multinacional europeia, por meio da análise 
de um Projeto global doravante denominado como "Projeto Turquia", que ratifica a relação direta entre os soft skills do gerente de projetos e o sucesso do referido projeto.

Este trabalho foi dividido nas seguintes seções: (1) introdução; (2) referencial teórico, onde serão apresentadas algumas teorias sobre soft skills; (3) metodologia, que explica como o estudo foi desenvolvido; (4) resultados obtidos e análise, que explora os resultados do estudo; (5) considerações finais; e, por último, as referências.

\section{Referencial Teórico}

Nas organizações, o gerenciamento de projetos é de responsabilidade do gerente de projetos, que precisa dispor de habilidades técnicas e não técnicas para a condução de suas atividades. O gerente de projetos deve saber navegar em diferentes níveis da organização, com a incumbência de fazer com que o projeto alcance o sucesso desejado. Dessa forma, o gerente de projetos é um profissional de grande visibilidade, pois se o projeto for bem sucedido, o mérito é da equipe de projetos por ele coordenada; mas se o projeto for um fracasso, a responsabilidade recairá sobre o gerente de projetos. Por isso, se faz necessário que este profissional possua um rol de competências que o permita alcançar os objetivos previamente determinados. Deste modo, nesta seção serão explorados os conceitos de gerenciamento de projetos globais e soft skills.

\subsection{Gerenciamento de Projetos Globais}

O gerenciamento de projetos globais, se comparado aos projetos locais, apresenta um maior grau de riscos e incertezas. Isso ocorre devido aos desafios e características envolvidas nesse tipo de projeto, além do que os projetos globais demandam uma maior complexidade na formação de equipes e em sua gestão (Watanuki et al.,2014). Contudo, mesmo que projetos globais apresentem desafios consideráveis, eles possuem também a característica de promover o desenvolvimento e um maior conhecimento para as empresas, além de permitir a ampliação de seus negócios (Boutellier et al., 1998). Deste modo, com a atuação em projetos globais, possivelmente as empresas tenham um incremento em seu portfólio de negócios, produtos e serviços, criando e mantendo uma rede de colaboração (networking) que agrega valor e parceiros à sua unidade (Steffey \& Anantatmula, 2011).

Como destaca Thamhain (2014), para implementar projetos globais nas organizações é requerido o uso efetivo de ferramentas e técnicas gerenciais em um ambiente organizacional local. Do mesmo modo, se faz necessário que empresas presentes em diferentes regiões 
geográficas adicionem essas ferramentas e técnicas em suas operações. Um aspecto importante neste contexto é que essa situação implica em lidar com culturas diferentes e por vezes divergentes. Watanuki et al. (2014) descrevem os aspectos importantes que devem ser levados em conta no gerenciamento de projetos globais, sendo eles: diferenças culturais, aspectos comportamentais, gestão de organizações ágeis e temporárias, aprendizado, tecnologia da informação e tomada de decisão.

Estudos realizados por Rodrigues (2010) em 34 projetos globais em multinacionais brasileiras com envolvimento atuante em 22 países destacam que as características culturais afetam diretamente o desempenho da equipe, tanto no âmbito técnico como no humano. Quanto ao risco nos projetos globais, maior ele se torna quando há uma alta distância cultural (Steffey, \& Anantatmula, 2011). Pode-se também notar a pouca importância dada à questão da multiculturalidade pelas empresas, sendo que essa situação gera impacto diretamente no desempenho e nos resultados dos projetos.

Portanto, os diversos projetos, sejam eles locais ou globais, não devem ser vistos como uma parte isolada dentro de uma empresa. Pelo contrário, os projetos devem ser parte das iniciativas globais da organização, onde o projeto estratégico deve contemplar o seu desenvolvimento no intuito de suportar planos maiores das organizações (Cleland, 1999).

Após essa breve retomada de aspectos teóricos sobre projetos globais, a próxima seção aborda os soft skills do gestor de projetos.

\subsection{Soft Skills}

Antes de prosseguir com o entendimento teórico do conceito soft skills é importante conceituar 'skill' e reconhecer a existência da dicotomia hard skills e soft skills. Skill é um termo em inglês cuja tradução é a habilidade de fazer uma atividade ou fazer bem um trabalho, especialmente porque o indivíduo o fez muitas vezes (Cambridge, 2017). A tradução pode tomar forma de "habilidade", "destreza". Para este artigo, adota-se o termo habilidade como tradução de skill.

As habilidades técnicas ou hard skills são aquelas definidas a partir do conhecimento técnico que o gerente de projetos tem sobre gerenciamento de projetos (Swiatkiewicz, 2014), como a elaboração de cronograma, nivelamento de recursos, criação de EAP (Estrutura Analítica do Projeto), definiçãa do caminho crítico, uso de software de gestão de projetos, etc. Os soft skills, por sua vez, são as habilidades interpessoais que fazem com que o gerente de 
projetos tenha boa atuação no âmbito do relacionamento com as partes interessadas do projeto (Robles, 2012). Aliás, a maior habilidade do gerente de projetos é fazer com que as pessoas envolvidas no projeto façam aquilo que elas precisam fazer dentro do prazo, escopo e custo combinados, sem esquecer-se dos requisitos de qualidade e satisfação do cliente. Para isso, é fundamental que o gerente de projetos possua soft skills, ou seja, saiba lidar de forma eficaz com as pessoas.

Para o PMI (2013, p. 274), soft skills são as habilidades interpessoais também conhecidas como "competências comportamentais que incluem capacidades tais como habilidades de comunicação, inteligência emocional, resolução de conflitos, negociação, influência, construção de equipe, e facilitação de grupos". Essa definição do PMI para soft skills foi adotada neste relato técnico.

O estudo de soft skills se dá porque o gerente de projetos é o líder da equipe responsável por alcançar os objetivos do projeto (PMI, 2013). Dessa forma, os soft skills dos gerentes de projetos é um tema que gera inquietação haja vista as organizações gastarem bilhões de dólares anualmente com treinamento para desenvolvê-los (Weber et al., 2009). Esses investimentos têm o objetivo de desenvolver as habilidades interpessoais dos funcionários no momento presente para que outros gastos sejam maximizados no futuro (Weber et al., 2009). As práticas de gerenciamento de projetos são maioritariamente influenciadas pelas habilidades soft em detrimento das habilidades hard (Pant \& Baroudi, 2008). Para esses autores, o verdadeiro sucesso do projeto vem quando o gerente de projetos aprende a como conseguir que as tarefas sejam feitas pelos demais. Nesta arena, os soft skills do gerente de projetos é o passaporte para o sucesso do projeto.

A lista de soft skills varia de profissão para profissão, podendo se apresentar também de forma diferente de acordo com o segmento de negócios. Para Venda (2017), por exemplo, o soft skill mais importante na área da Saúde é a empatia que se confirma pela boa relação do profissional de saúde com seus colegas e pacientes. Essa realidade na área da saúde consiste na habilidade de se colocar no lugar do outro. Já para os profissionais de gerenciamento de projetos, os principais soft skills são, segundo Heldman (2010): Liderança; Comunicação; Saber Ouvir; Organização; Gestão do Tempo; Planejamento; Resolução de Problemas; Construção de Consenso; Resolução de Conflitos; Negociação e Trabalho em Equipe. O PMI (2013) descreve importantes soft skills tais como: liderança, construção de equipes, motivação, comunicação, influência, tomada de decisões, consciência política e cultural, negociação, ganho de confiança, gerenciamento de conflitos e coaching. Para este trabalho, os soft skills analisados são: 
liderança, comunicação, influência, ganho de confiança e coaching pois esses foram os observados no projeto global Turquia.

A seguir, são apresentados os aspectos metodológicos adotados para a realização deste estudo.

\section{Metodologia}

O presente estudo trata-se de um relato técnico, que descreve uma real experiência em contexto organizacional. Apesar de seu teor prático e de refletir o pensamento dos autores, todo o rigor científico e metodológico deve ser seguido (Biancolino et al., 2012).

Diante do tipo de questão abordada neste estudo - como o uso dos soft skills do gerente de projetos favorece o gerenciamento de projetos globais? - optou-se pelo estudo de caso único descritivo, do tipo holístico, como método de pesquisa qualitativa, que é ideal para situações como esta em que o pesquisador deseja explorar um fenômeno em profundidade (Creswell, 2010). Estudos de casos geralmente representam o método predileto para questões do tipo "como" e "por que" (Yin, 1989).

Para fins de confidencialidade, a empresa em questão receberá um nome fictício: TravelMax. Para que não seja criado nenhum constrangimento, os profissionais envolvidos também receberão nomes falsos para representar o gerente de projetos antecessor: Marcelo e sua sucessora: Mônica.

Neste estudo, a unidade de análise é o Projeto Turquia que durou de novembro de 2016 até maio de 2017, na empresa TravelMax, localizada em São Paulo. O motivo que ratifica esta escolha está no fato do Projeto Turquia atender aos pré-requisitos da pesquisa: é um projeto global cujo êxito foi reconhecido como atrelado ao uso de soft skills da gerente de projetos Mônica. A técnica de coleta de dados escolhida foi a observação participante (Queiroz et al., 2007) sobre o Projeto Turquia com o uso de imparcialidade por parte do pesquisador para avaliar o caso proposto, além da consulta a documentos de registros do projeto em arquivos eletrônicos disponibilizados pelo time do Projeto Turquia, tais como atas de reuniões, documentos de status report, plano do projeto, documentos de lições aprendidas que serviram para a triangulação (Yin, 2001) a fim de garantir confiabilidade à pesquisa.

Este relato técnico dirige o foco para um contexto restrito refletido na proposição que diz que o uso de soft skills pelo gerente de projetos é um fator de relevância para o sucesso do gerenciamento de projetos globais. Foram analisadas as evidências do estudo de caso em 
questão por meio da disposição dos fatos em ordem cronológica, destacando as situações onde os soft skills do gerente de projetos foram cruciais para um bom desfecho das problemáticas que surgiram ao longo do Projeto Turquia.

Portanto, é sob o olhar dos soft skills: liderança, comunicação, influência, ganho de confiança e coaching (PMI, 2013) que o Projeto Turquia foi analisado. Destaca-se que esse foi um caso de projeto considerado bem sucedido com um time dividido entre: França, Espanha, Argentina, Colômbia, Estados Unidos e Turquia, gerenciado a partir do escritório local em São Paulo, Brasil.

\section{Apresentação e Discussão dos Resultados}

Este relato técnico descreve o estudo de caso do Projeto Turquia desde a saída do gerente de projetos Marcelo, com o desfecho do Projeto Ucrânia, com a subsequente transferência de conhecimento para a gerente de projetos Mônica, responsável por iniciar e finalizar o Projeto Turquia. Ao longo do estudo de caso, foi dada ênfase na utilização dos soft skills de Mônica durante o Projeto Turquia para demonstrar a relevância destes no sucesso do referido projeto global.

\subsection{Caracterização do caso}

O objeto de análise neste relato é a gestão de um projeto de implantação de um portal web na Turquia. Para tanto, serão descritos todos os desafios vividos pelo gerente de projetos, este localizado no Brasil, que precisou gerenciar uma equipe remota distribuída em diversos países. A TravelMax iniciou em novembro de 2016 o projeto global aqui analisado. O objetivo deste projeto era implantar um portal self service na Turquia para atender aos clientes de pequeno e médio porte do escritório comercial daquele país. Esse projeto denominado como "Projeto Turquia" fazia parte de um Programa chamado "WWW" constituído por três projetos: Projeto Ucrânia, Projeto Turquia e Projeto Suíça. Logo, se faz necessário explicitar que ao observar a relação entre diversas localidades e a gestão de projetos, este relato técnico irá cobrir o final da implantação do Projeto Ucrânia e todo o ciclo de vida do Projeto Turquia. O período aqui delimitado compreende um processo de transição que possibilitará descrever a mudança da gestão do projeto numa tentativa da empresa TravelMax de conferir um bom desempenho para o Projeto Turquia, uma vez que o Projeto Ucrânia não foi finalizado no prazo inicialmente planejado. 
Marcelo gerenciou o Projeto Ucrânia e Mônica cuidou do Projeto Turquia. Ambos enfrentaram muitos desafios inerentes à situação: gerenciar um projeto global com equipes remotas e espalhadas em diferentes países, com culturas, idiomas, fusos horários e costumes diferentes. Neste cenário, onde ambos os gerentes de projetos possuíam alto nível de senioridade, as habilidades técnicas de gestão de projetos não foram as mais relevantes para diferenciar o bom desempenho do projeto. Contudo, após a construção do estudo de caso foi possível notar que os soft skills impactaram de alguma forma na performance do projeto estudado.

\subsection{Caracterização da organização e do problema analisado}

A empresa alvo deste estudo de caso é a TravelMax, uma multinacional europeia fundada há mais de 30 anos, que é líder global em soluções de TI para os segmentos de turismo e viagens. Seu perfil corporativo é de uma empresa provedora de soluções de tecnologia e serviços que conecta todo o ecossistema de viagens: agências de viagens, agentes de turismo, empresas aéreas e passageiros. O negócio da TravelMax é bem amplo porque envolve também aeroportos, agências de aluguel de carro, operadoras de cruzeiro marítimo, operadores ferroviários, hotéis e provedores de seguros. Ela conta com escritórios em mais de 190 países e uma força de trabalho de mais de 15.000 colaboradores.

Uma característica singular da TravelMax é a presença de seus escritórios nos cinco continentes o que a torna uma empresa global. Além disso, a empresa processa mais de 55.000 transações por segundo em horário de pico de acordo com o relatório global da empresa (2016). Cabe salientar que uma empresa global precisa ser amparada por projetos globais que transcendam as barreiras geográficas dos países promovendo negócios com produtos ou serviços globais (Fleury \& Fleury, 2003; Piscopo \& Sbragia, 2012).

\subsection{Contexto do Projeto Turquia}

Ao compor o time do projeto Turquia, Mônica recebe um repasse de conhecimento ao longo de três dias do seu antecessor - o gerente de projetos Marcelo - que lhe explica questões de integração, escopo, tempo, custos, qualidade, recursos humanos, comunicação, riscos, aquisições e partes interessadas do Projeto Ucrânia que acabara de ser implantado e estava na etapa de suporte pós-implantação. Os gerentes de projetos optam por usar as 10 áreas de conhecimento do PMBOK (Project Management Body of Knowledge) como guia para esse 
repasse de conhecimento na mudança de gestão do projeto. O Projeto Turquia possui basicamente o mesmo escopo do Projeto Ucrânia - a única ressalva está no país de destino de implantação do Portal Web. Um breve resumo do projeto Turquia é fornecido a seguir usando as 10 áreas de conhecimento do PMBOK (PMI, 2013).

A integração do projeto consiste em manter os times trabalhando em sintonia com os objetivos do projeto. Os membros do projeto estão situados em: Miami (EUA), Bogotá (Colômbia), Buenos Aires (Argentina), Madri (Espanha), Nice (França), Istambul (Turquia) e São Paulo (Brasil). Já o escopo macro do projeto Turquia é disponibilizar um web portal amigável e atrativo, com um ambiente de serviços self-service, para atender as agências de turismo de pequeno e médio porte da TravelMax no mercado turco. O cronograma do projeto é definido na primeira etapa do Projeto Turquia, chamada “Concepção e Planejamento". Todas as atividades são distribuídas ao longo de seis meses compreendidos de novembro de 2016 a maio de 2017. A área de conhecimento custos é gerenciada pelo PMO (Project Management Office) na França, portanto, não aplicável para o gerenciamento deste projeto. Com relação à qualidade, documentos de gestão do Projeto Turquia quase sempre são conferidos pelo processo de revisão em pares (peer review). Já para as entregas técnicas relacionadas ao portal, há uma etapa dedicada apenas a esse intuito chamada de homologação, com dois ciclos de testes: o primeiro ciclo de testes a ser efetuado pelos times internos do projeto localizados na Espanha; e, o segundo ciclo de testes executado pelo time do escritório comercial na Turquia, além de uma etapa piloto com testes realizados novamente pelos mesmos times em ambiente de produção. Com relação a recursos humanos, os profissionais envolvidos no Projeto Turquia são os mesmos do Projeto Ucrânia e ocupam os seguintes cargos: analistas, desenvolvedores, líderes técnicos, gerentes de linha, gerentes de programa, além da própria gerente de projetos Mônica, cerca de 20 pessoas. Trata-se de times com diferentes localizações geográficas, idiomas, fusos horários e culturas. A comunicação do projeto Turquia baseia-se nas trocas de emails e chamadas telefônicas. Os principais eventos de comunicação do Projeto são as reuniões diárias que Mônica mantinha com o time de desenvolvedores dos EUA, Brasil, Colômbia e Argentina e as reuniões semanais com o PMO da França, além da publicação semanal de um relatório de status do projeto. A gestão de riscos do Projeto Turquia é baseada na identificação da descrição do risco, impacto e plano de resposta ao risco com publicação semanal para o PMO da França. A área de aquisições também não é explorada pelo Projeto Turquia, pois nenhuma aquisição se faz necessária ao longo do Projeto, a não ser pelas contratações de alguns recursos terceiros que compunham o time do Projeto Turquia, o que não demandou nenhuma ação da 
gerente de projetos Mônica. Por último, com relação às partes interessadas, todo o time de projetos é apresentado para a gerente de projetos Mônica por meio de email ou chamadas telefônicas, salvo exceção de seu superior direto que ela conheceu pessoalmente. Destaca-se que um de seus maiores desafios foi conquistar a confiança e credibilidade do gerente de programas localizado na França.

O programa WWW visava disponibilizar o mesmo portal para três distintos mercados: Ucrânia, Turquia e Suíça, sendo que existiam algumas especificidades a serem tratadas em cada país. Entretanto, somente os países Ucrânia e Turquia foram atendidos, pois a liderança global da TravelMax, com base nos atrasos e custos excedidos pela primeira implantação na Ucrânia, decidiu por cancelar a implantação do portal na Suíça e encerrou o programa com apenas duas implantações.

\subsection{Tipo de Intervenção e mecanismos adotados}

Mônica, enquanto gerente do Projeto Turquia, enfrentou muitos desafios inerentes a projetos globais. A seguir são descritos alguns destes desafios e como o uso de seus soft skills ajudou Mônica a fazer do Projeto Turquia um projeto de sucesso.

Lideranca: a gerente de projetos Mônica, recém-chegada na TravelMax, se deparou com um histórico ruim do projeto anterior - Projeto Ucrânia - que foi entregue com problemas de prazo e custo, além da perda de credibilidade do gerenciamento de projetos perante a liderança da companhia. No entanto, ela não se intimidou e fez uso de suas habilidades de liderança. Assim, para fortalecer sua liderança, ela institui uma agenda de reuniões diárias de 30 minutos para acompanhar as atividades do time de desenvolvedores. As reuniões se deram em espanhol ou inglês via chamada telefônica. Durante as reuniões, a gerente de projetos aproveitou para inteirar-se mais da parte funcional do projeto e estar, de alguma forma, próxima do time remoto distribuído nos EUA, Argentina, Colômbia e Brasil. As reuniões foram usadas por Mônica para estar à frente do projeto como líder responsável pelo time e também facilitadora na solução dos problemas que surgiam no dia-a-dia.

Comunicacão: Para o PMI (2013), o gerente de projetos passa a maior parte do seu tempo realizando comunicações dentro do projeto. Mas, quando se trata de um projeto global, as barreiras de comunicação são muitas, sendo elas a cultura, o idioma, o fuso horário, a localização, a infraestrutura, ou seja, o ato de se comunicar em projetos globais ganha ingredientes que desafiam muito o soft skill de comunicação do gerente de projetos. Mônica 
possui inglês e espanhol fluentes, e essa característica a ajudou sobremaneira durante todo o projeto. Como lição aprendida do projeto anterior, Mônica optou por emails curtos e objetivos para facilitar o entendimento de seus interlocutores. Além disso, ela promoveu relatórios semanais acerca do andamento do Projeto Turquia em um formato bastante visual que demonstrou as etapas do projeto com suas datas de início e término em dois formatos: previsto versus realizado. A exposição dos percentuais de conclusão de cada etapa também facilitou o entendimento de quem lê o relatório. Além disso, ela aplicou um sistema de cores (verde, amarelo e vermelho) como artifício visual para denotar se o Projeto Turquia estava dentro do planejado (verde), com risco de atraso (amarelo) ou atrasado (vermelho). No caso do vermelho, Mônica elaborou e publicou um plano de ação claro com papéis, responsabilidades e datas alvo. Os relatórios semanais do projeto que foram gerados por Mônica sofriam uma revisão em pares por um de seus superiores. Isso gerou nela uma disciplina por uma escrita cada vez mais assertiva, até chegar ao ponto de que seu superior direto não mais fazia a revisão de seus textos, por confiar na comunicação de Mônica, que havia conquistado um padrão de excelência.

Influência: tanto o histórico profissional de Mônica, quanto sua experiência profissional como gerente de projetos a ajudaram a influenciar pessoas dentro do Projeto Turquia. Ela usou o seu know-how aliado ao seu soft skill de influenciar pessoas para convencer o time do projeto quanto às suas ideias. Uma de suas ideias inovadoras foi o fato de ela ter convencido a liderança global do Projeto Turquia a executar a etapa de testes de uma forma diferente da usada no Projeto Ucrânia. A mudança proposta por Mônica: cada usuário responsável pela realização dos testes, ao encontrar um erro no portal, deveria registar tal erro em uma base central e única disponível em um ambiente corporativo e compartilhado. Antes, os erros eram simplesmente reportados via email pelos usuários-chave e o próprio time de desenvolvedores era responsável por realizar o registro dos erros reportados bem como a correção dos mesmos, o que gerava acúmulo de funções. Essa mudança gerou eficiência para o time de desenvolvedores que ficou focado, então, apenas na solução dos erros reportados gerando escalabilidade na correção dos defeitos encontrados na etapa de testes. O fato de Mônica ter alcançado a aprovação para descentralizar o registro de "falhas a corrigir", comprovou para a equipe de projetos a sua capacidade de influenciar pessoas hierarquicamente superiores.

Ganho de confianca: quando Mônica iniciou no Projeto Turquia ela foi alertada por um gerente sênior da companhia de que seu maior desafio era ganhar a confiança do gerente de programas que ficava na França. O gerente de projetos anterior não desenvolveu um bom relacionamento com o gerente de programas e essa era uma das razões que justificou a mudança 
na gestão de projetos. Para se aproximar da distância continental entre Mônica e o gerente de programas, ela sugeriu uma agenda de reuniões semanais com ele, o que ocorreu com êxito durante todo o projeto. Nessas reuniões, Mônica explicava a situação do Projeto Turquia, repassava os progressos das atividades, além dos riscos. O gerente de programas, pouco a pouco, desenvolveu confiança na gestão de Mônica, que cumpria os prazos acordados com ele. Entretanto, quando ocorriam exceções, ela informava antecipadamente ao gerente de programas tão logo percebia um descumprimento de prazo iminente. Além disso, Mônica estipulou critérios de comunicação com o gerente de programas - cuja ausência incomodava o gerente de programas na gestão anterior - convencionando que tipo de comunicação e qual audiência Mônica poderia atingir com seus emails.

Coaching: Mônica percebeu, ao longo da etapa de desenvolvimento da solução web, que um de seus analistas apresentava desmotivação para o trabalho. Tal analista repassava datas para suas atividades, mas raramente as cumpria. Mônica identificou que o analista em questão possuía potencial, pois tinha muitos anos de trabalho na empresa, conhecia bem as regras de negócio e as soluções da TravelMax. A demissão não parecia ser o melhor caminho; então, Mônica convocou uma reunião com o analista, explicando os pontos de melhorias sobre o seu trabalho e questionando planos de ação para melhorá-los. Juntos, Mônica e o analista chegaram a um consenso, e daí para frente Mônica não identificou demais problemas com o cumprimento de prazos do referido analista.

\section{Considerações Finais}

O resultado do Projeto Turquia ratificou o objetivo de pesquisa deste relato técnico. A questão de pesquisa "como o uso dos soft skills do gerente de projetos favorece o gerenciamento de projetos globais?" foi respondida com a demonstração de como os soft skills: liderança, comunicação, influência, ganho de confiança e coaching (PMI, 2013) analisados de Mônica foram realmente relevantes no gerenciamento do Projeto global Turquia. Além das evidências descritas na seção anterior, o documento de lições aprendidas do projeto comprovou dois fatos: (1) o Projeto Turquia foi considerado um projeto de sucesso pela liderança do projeto - foi entregue dentro do prazo, com o custo e escopo combinados inicialmente; e, (2) o sucesso do Projeto Turquia foi atrelado ao estilo de gestão da gerente de projetos Mônica (liderança, comunicação, influência, confiança e coaching). Vale ressaltar que esta última constatação 
também foi ratificada por emails que Mônica recebeu da liderança global do projeto após o seu término.

Do documento de lições aprendidas, cerca de $72 \%$ das lições tiradas do projeto foram consideradas positivas, ou seja, há mais procedimentos realizados no Projeto Turquia para serem replicados em futuros projetos que o contrário. Das lições consideradas positivas, o estilo de gestão de Mônica é mencionado em cerca de $85 \%$ das ocorrências - esta é uma evidência de que os soft skills de Mônica têm relação com a percepção de sucesso do Projeto Turquia. De fato, destaca-se que, gerenciar um projeto de tamanha abrangência requer mais que conhecimentos técnicos e boas práticas em gerenciamento de projetos. Um projeto global requer habilidades específicas do gerente de projetos, principalmente os soft skills, que são aquelas inerentes à personalidade do profissional para lidar com adversidades.

Portanto, os desafios que podem ser destacados aqui são: trabalhar com equipes geograficamente distantes; fazer comunicações por meio de diferentes canais em um idioma que não é a língua nativa da maioria das partes envolvidas; apoiar-se numa infraestrutura que é passível de falhas para realizar as reuniões do projeto; enfrentar as diferenças culturais e tratar as partes interessadas levando em consideração tais diferenças; ser flexível para atuar num projeto com diferentes fusos horários. Deste modo, ao fim deste relato pode ser dito que estes são alguns dos desafios enfrentados pelo gerente de um projeto global. Consequentemente, ratifica-se a importância dos soft skills dos gerentes de projetos globais na conquista de um bom desempenho.

Os resultados deste estudo oferecem contribuições para profissionais e estudantes da área de gerenciamento de projetos interessados em compreender a relevância de soft skills no gerenciamento de projetos globais na medida em que evidencia as contribuições dos soft skills para o sucesso de projetos globais; também apresenta os desafios desse tipo de projeto e diferentes habilidades que podem contribuir para sua superação. Por fim, pode-se dizer que os soft skills são habilidades difíceis de quantificar (Araújo, 2016), porém, tais habilidades são passíveis de serem desenvolvidas. Dada esta relevância, o desenvolvimento de habilidades consideradas soft skills poderá ser objeto de pesquisas futuras. 


\section{Referências}

Araújo. C., \& Pedron, C. D. (2016). A importância dos soft skills e o tipo de personalidade dos gerentes de projetos de TI. JPBReview, 1(1), 40-59.

Biancolino, C. A., Kniess, C. T., Maccari, E. A., \& Rabechini Jr., R. (2012). Protocolo para Elaboração de Relatos de Produção Técnica. Revista Gestão e Projetos, 3(2), 294-307.

Boutellier, R.; Gassmann, O.; Macho, H.; Roux, M.; (1998). Management of dispersed product development teams: the role of information Technologies. Revista R\&D Management (Vol. 28 , pp. 13-25).

Cambridge. (2017). Tradução de "skill" - Dicionário Inglês-Português. Retrieved July 11, 2017, from http://dictionary.cambridge.org/pt/dicionario/ingles-portugues/skill

Cleland, D. I.;(1999). Project management: strategic design and implementation. 3rd ed. New York. Ed. McGraw-Hill.

Creswell, John W. (2010). Projeto de pesquisa: métodos qualitativo, quantitativo e misto; tradução Magda Lopes, 3a. ed. Porto Alegre: ARTMED, 296.

Fleury, A. C., \& Fleury, M. T. L. (2003). Estratégias competitivas e competências essenciais: perspectivas para a internacionalização da indústria no Brasil. Gestão \& Produção, 10(2), 129-144.

Heldman, K., \& Heldman, W. (2010). CompTIA Project Study Guide: (PK0-003). John Wiley $\&$ Sons.

Pant, I., \& Baroudi, B. (2008). Project management education: The human skills imperative. International Journal of Project Management, 26(2), 124-128. https://doi.org/10.1016/j.ijproman.2007.05.010

Piscopo, M. R., \& Sbragia, R. (2012). Key Issues in Global Technological Innovation Projects. Revista de Gestão e Projetos, 3(1), 4.

Piscopo, M. R. (1970, January 01). Strategic Issues em projetos globais de inovação tecnológica em empresas multinacionais brasileiras. Retrieved July 11, 2017, from http://www.teses.usp.br/teses/disponiveis/12/12139/tde-05052010-123856/pt-br.php

PMI. (2013). A Guide to the Project Management Body of Knowledge ( PMBOK® Guide ) Portuguese (5th ed.). Pennsylvania, USA: Project Management Institute, Inc.

Queiroz, D. T., Vall, J., Souza, Â. M. A., \& Vieira, N. F. C. (2007). Observação participante na pesquisa qualitativa: conceitos e aplicações na área da saúde. Rev. enferm. UERJ, 276-283.

Robles, M. M. (2012). Executive Perceptions of the Top 10 Soft Skills Needed in Todays Workplace. Business Communication Quarterly, 75(4), 453-465.

Rodrigues, I. (2010). Cultura e Desempenho de Equipes de Projetos Globais: um estudo em empresas multinacionais brasileiras (Doctoral dissertation, Universidade de São Paulo).

Steffey, R. W.; Anantatmula, V. S.; (2011). International projects proposal analysis: Risk assessment using radial maps. Project Management Journal. (Vol. 42, No. 3, Pp. 62-74). PMJ.

Swiatkiewicz, O. (2014). Competências transversais, técnicas ou morais: um estudo exploratório sobre as competências dos trabalhadores que as organizações em Portugal mais valorizam. Cadernos EBAPE.BR, 12(3), 633-687.

Thamhain, H. J.; (2014). Managing technology based projects: Tools, techniques, people and business processes (1a ed.). EUA. Wiley.

Venda, D. (2017). "Soft Skills na prática clínica", Dr. Diogo Medina | III Jornadas Médicas da NOVA. (n.d.). Consultado em 15 de junho de 2017, a partir de http://revistafrontal.com/educacao-medica/nms-fcm-nova/iii-jornadas-medicas-danova/soft-skills-na-pratica-clinica-dr-diogo-medina-iii-jornadas-medicas-da-nova/

Watanuki, H. M., Nadae, J. D., Carvalho, M. M., \& Moraes, R. D. (2014). Gestão de projetos 
internacionais: um estudo bibliométrico. Gestão \& Produção, 21(3), 660-675. doi:10.1590/0104-530x394

Weber, M. R., Finley, D. A., Crawford, A., \& Rivera, D. (2009). An exploratory study identifying soft skill competencies in entry-level managers. Tourism and Hospitality Research, 9(4), 353-361.

Yin, R. K. (2001). Estudo de caso: planejamento e métodos. Catalogação na publicação: Mônica Ballejo Canto (Vol. 2). https://doi.org/10.1088/1751-8113/44/8/085201. 